\title{
Use of Prostate-Specific Antigen (PSA) Isoforms For The Detection of Prostate Cancer in Men With a PSA Level Of 3-10 ng/ml: A Zimbabwean Perspective
} isoforms

\section{* Hilda T Marima- Matarira}

\section{Steven Uladi}

\section{Prosper Jambwa}

\section{Christopher Mafuva}

Department of Chemical Pathology, University of Zimbabwe College of Health Sciences, P.0. Box A178, Harare, Zimbabwe. * Corresponding author

Department of Chemical Pathology, University of Zimbabwe College of Health Sciences, P.0. Box A178, Harare, Zimbabwe.

Department of Chemical Pathology, University of Zimbabwe College of Health Sciences, P.0. Box A178, Harare, Zimbabwe.

Department for Health, University of Bath, Bath, BA 7AY, United Kingdom

\section{ABSTRACT}

Total PSA (tPSA) has been used to diagnose prostate cancer although its performance as a screening test has several limitations including limited specificity. The main objective of the study was to determine the use of the PSA isoforms (free PSA, complex PSA and ratio of free/total PSA) in diagnosing prostate cancer among Zimbabwea men with tPSA levels between 3 and $10 \mathrm{ng} / \mathrm{ml}$. A cross sectional study was done on 44 men attending a Urology Clinic at Harare Hospital (mean age $=70 \mathrm{yrs}$ ). If tPSA was between 3 and $10 \mathrm{ng} / \mathrm{ml}$ and the attending urologist requested a prostate biopsy a written consent was sought and the sample was analyzed for free and complexed PSA (cPSA). A follow up was made on the biopsy results. Statistical methods were then used to determine the use of the PSA isoforms (fPSA, CPSA and off/tPSA ratio) in diagnosing prostate cancer. An increase in the fPSA significantly lowered the risk of developing prostate cancer (OR 0.01, $p=0.003$ ). However, the ratio off/tPSA was more predictive of the occurrence of prostate cancer. Total PSA and cPSA were not significant ( $p=0.753$ and 0.237 respectively). The ratio PSA test was highly predictive (AUC=0.921, $p=0.002)$ than free PSA (AUC=0.908, $p=0.003)$. The study conforms to other reports postulating that $f$ / $t P S A$ ratio can aid in the diagnosis of prostate cancer in the $3-10 \mathrm{ng} / \mathrm{ml}$ range as compared to the use of tPSA alone with $\mathrm{f} / \mathrm{tPSA}$ ratio being more predictive. The use of cPSA remains uncertain. Not withstanding resource limitations, there is a need for larger national cohort studies which may run concurrently with CaP awareness campaigns.

\section{BACKGROUND}

Prostate-specific antigen (PSA) is a widely used marker for staging and monitoring of prostate cancer. ${ }^{1,2}$ PSA is a protease secreted by both normal and malignant prostatic epithelial cells with much secreted into the seminal fluid during ejaculation. ${ }^{2}$ Minor amounts normally leak into circulation although the release of PSA into circulation increases with prostate disease. ${ }^{2,3}$ Cancer of the prostate $(\mathrm{CaP})$ is the second most commonly diagnosed cancer among men in the world. Its identification has been characterised by false positives associated with benign prostatic hyperplasia (BPH) ${ }^{1,3}$

The importance of PSA as a diagnostic tool for CaP came into light following a study in USA that determined elevation of total PSA (tPSA) in men with newly diagnosed, untreated prostate cancer. ${ }^{4}$ Complex PSA (cPSA) is that part of PSA which is bound to antichymotrypsin. In prostate cancer, cPSA constitutes the bulk component compared to free PSA (fPSA). ${ }^{2,5}$ Between 25\% and $40 \%$ of men with tPSA in the range $4.0-10 \mathrm{ng} / \mathrm{ml}$ will have $\mathrm{CaP}$. The implication is that $60-75 \%$ of men with tPSA values in the range $4.0-10 \mathrm{ng} / \mathrm{ml}$ will undergo unnecessary biopsies. ${ }^{6} \mathrm{On}$ the contrary, between 20 and $40 \%$ of cancers are missed when a tPSA threshold of $4.0 \mathrm{ng} / \mathrm{ml}$ is used, a large proportion of which are moderately differentiated but locally confined hence these may benefit from early detection. ${ }^{7}$ Men with PSA values of between 2.0 and $3.0 \mathrm{ng} / \mathrm{ml}$ have been shown to have seven times chances of developing aggressive prostate cancer within 10 years when compared to men whose tPSA levels are less than $1.0 \mathrm{ng} / \mathrm{ml}^{8}$

Black men have been shown to have a high incidence of prostate cancer. This is because they have larger tumour volumes at all stages. ${ }^{9,10}$ Morgan et $a l^{10}$ formulated some race specific reference ranges as follow:

- 40 to 49 years - 0 to $2.5 \mathrm{ng} / \mathrm{ml}$ (whites); 0 to $2.0 \mathrm{ng} / \mathrm{ml}$ (blacks)

- 50 to 59 years - 0 to $3.5 \mathrm{ng} / \mathrm{ml}$ (whites); 0 to $4.0 \mathrm{ng} / \mathrm{ml}$ (blacks)

- 60 to 69 years - 0 to $3.5 \mathrm{ng} / \mathrm{ml}$ (whites); 0 to $4.5 \mathrm{ng} / \mathrm{ml}$ (blacks)
- 70 to 79 years - 0 to $3.5 \mathrm{ng} / \mathrm{ml}$ (whites); 0 to $5.5 \mathrm{ng} / \mathrm{ml}$ (blacks)

Overall, tPSA levels have been shown to increase with age, due to higher prevalence of BPH. ${ }^{11}$ The use of tPSA has limited specificity ${ }^{[2,12]}$. The use of the ratio of fPSA to tPSA (f/tPSA) improves the sensitivity of cancer detection when tPSA is in the "grey zone" of $4-10 \mathrm{ng} / \mathrm{ml}^{13,14,15}$ In this paper, we evaluate the use of fPSA, cPSA and the ratio f/tPSA in diagnosing CaP among Zimbabwean men.

\section{METHOD}

In this cross-sectional study, 44 men presenting at Harare Central Hospital Urology Clinic were enrolled in the study. The mean age of the participants was 70 years (Range: 46 to 92). These men would have initially presented themselves to the Casualty officer at the hospital's out patients department and had been thereafter referred to the Urology Clinic for further diagnosis and management. At the clinic, a tPSA screen test would be ordered if digital rectal examinations (DRE) were abnormal. Participants were included in the study if they met the following criteria:

- Adult men aged 18 years and above

- Men with a tPSA level between 3-10 ng/ml from blood drawn at time of initial evaluation

- Participants with a prostate biopsy request

- Men who would have consented

Participants excluded in the study were; men under treatment for prostate cancer, men less than 18 years, men with a tPSA outside the $3-10 \mathrm{ng} / \mathrm{ml}$ range, men without a biopsy request and men who did not consent to participate.

Written informed consent was sought from each participant and when granted questionnaires soliciting demographic and clinical parameters were administered. Consenting men with a tPSA level of between 3 and $10 \mathrm{ng} / \mathrm{ml}$ and a prostate biopsy request were enrolled in the study. Left over blood samples from the tPSA level determination was accessed for the determination of fPSA and cPSA. Patients' records were also accessed to ascertain 
the prostate biopsy findings. One urologist did the transurethral resection of the prostate (TURP) biopsies and two pathologists read the histology. To determine the outcome, fPSA, tPSA, cPSA and their calculated ratios were used to determine the diagnostic ability of these isoforms in correlation to the biopsy results.

Total PSA assay was done using a Maglumi Total PSA (CLIA) (Shenzhen New Industries Biomedical Engineering Co. Ltd, Shenzhen, China) kit from the instruments supplier. The principle of the test is based on a sandwich immunoluminometric method. Free PSA assay was done using a Maglumi free PSA (CLIA) (Shenzhen New Industries Biomedical Engineering Co. Ltd, Shenzhen, China) kit. The principle of the test is also based on a sandwich immunoluminometric method. The cPSA assay was done using the Advia Centaur cPSA reagent pack (Siemens Healthcare Diagnostics, Deerfield, IL), which is a twostep sandwich assay using direct chemiluminetric technology. Bio-Rad Lymphocheck Tumor Marker Plus Control level 1and 3 (BIO-RAD Laboratories, California, United States) were used as controls in the Total PSA assay. Sample results were only taken if the control values obtained for levels 1 and 3 were within \pm 3 SD. A kit internal control was used as control material for the fPSA assay. Sample results were only taken if the control values were within the manufacturer's reference range. BIO-RAD Lympocheck Tumor Plus Control level 1 and 3 (BIO-RAD Laboratories, California, United States) were used as controls for the complexed PSA assay. Results were acceptable as levels 1 and 3 were within \pm 3 SD.

\section{RESULTS}

Data used in the analysis was drawn from a cross-sectional study on 44 male participants attending Urology Clinic at Harare Hospital. The R version 3.0.1 (2013-05-16) statistical software was used in developing most of the statistical analysis with the exception of the ROC analysis. SPSS was used in ROC curve analysis. The study used non-parametric statistical methods such as Mann-Whitney test estimate the possibility of differences between two population samples (prostate cancer and $\mathrm{BPH}$ cases), exact logistic regression was used to obtain odds ratios. Only 5 out of $44(11.4 \%)$ of the participants had histologically confirmed prostate cancer (adenocarcinoma). Explanatory variables measured were: tPSA mean $5.9 \mathrm{ng} / \mathrm{ml}$ (SD 2.1), fPSA mean $0.9 \mathrm{ng} / \mathrm{ml}$ (SD 0.6), cPSA mean 4.1 (SD 2.0) and ratio f/ tPSA mean 14.9 (SD 1.8) as shown in Table 1.

Table 1: Summary Statistics

\begin{tabular}{|c|c|c|c|c|}
\hline \multirow[b]{2}{*}{$\begin{array}{l}\text { Variable } \\
\text { (mean; SD) }\end{array}$} & \multirow[b]{2}{*}{$\begin{array}{l}\text { Total } \\
(\mathrm{n}=44)\end{array}$} & \multicolumn{2}{|c|}{ Biopsy results } & \multirow[b]{2}{*}{ p-value ${ }^{a}$} \\
\hline & & $\begin{array}{l}\text { Prostate } \\
\text { cancer } \\
(\mathrm{n}=5)\end{array}$ & $\begin{array}{l}\mathrm{BPH} \\
(\mathrm{n}=39)\end{array}$ & \\
\hline tPSA & $5.9 ; 2.1$ & $6.2 ; 2.6$ & $5.7 ; 2.1$ & 0.7532 \\
\hline fPSA & $0.9 ; 0.6$ & $0.3 ; 0.1$ & $1.0 ; 0.7$ & $0.0033^{* *}$ \\
\hline cPSA & $4.1 ; 2.0$ & $5.6 ; 3.2$ & $3.9 ; 1.9$ & 0.2365 \\
\hline $\begin{array}{l}\text { Ratio PSA } \\
\text { (f/tPSA) }\end{array}$ & $14.9 ; 1.8$ & $4.8 ; 0.6$ & $16.2 ; 12.8$ & $0.0024^{* *}$ \\
\hline
\end{tabular}

The p-value ${ }^{a}$ was determined using the Manny-Whitney twosample mean comparison. A single asterisk $\left({ }^{*}\right)$ represents a significant difference, while double asterisks $\left.{ }^{* *}\right)$ represent very significant differences and triple asterisks $\left({ }^{* * *}\right)$ depict highly significant differences.

Variables found significant using the Manny-Whitney test (alternative to the t-test, used when assumptions of the t-test are not met) were fPSA ( $p=0.003$ ) and consequently as a ratio to total PSA ( $\mathrm{p}=0.002)$. Total PSA and cPSA were not significant $(\mathrm{p}=0.753$ and 0.237 respectively).

The exact logistic regression analysis was used to measure association between the occurrences of prostate cancer with the isoforms and ratio (f/tPSA). Results show that an increase in the fPSA significantly lowered the risk of developing prostate cancer (OR 0.01, p=0.003). However, the ratio of $\mathrm{f} / \mathrm{tPSA}$ is more predictive of the occurrence of prostate cancer. An increase in the ratio is likely to reduce the chances of prostate cancer as depicted in Table 2.

Table 2: Univariate logistic regression

\begin{tabular}{|l|l|l|}
\hline Variable & Odds ratio & p-value \\
\hline tPSA & 1.07 & 0.7553 \\
\hline fPSA & 0.01 & $0.0031^{* *}$ \\
\hline cPSA & 1.37 & 0.1228 \\
\hline f/tPSA & 0.44 & $0.0005^{* * *}$ \\
\hline
\end{tabular}

The p-value ${ }^{\mathrm{a}}$ was determined using the Exact logistic regression. A single asterisk $\left(^{*}\right)$ represents a significant difference, while double asterisks $\left.{ }^{* *}\right)$ represent moderately significant differences and triple asterisks (***) depict highly significant differences.

A ROC was fit in SPSS 17 to compare diagnostic ability of PPSA and ratio $\mathrm{f} / \mathrm{tPSA}$ to the biopsy outcome as depicted in Figure 1. The area under curve (AUC) was used as a measure of comparison between the tests.

Fig 1. ROC analysis comparing fPSA and ratio f/tPSA relative to biopsy outcome.

\section{ROC Curve}

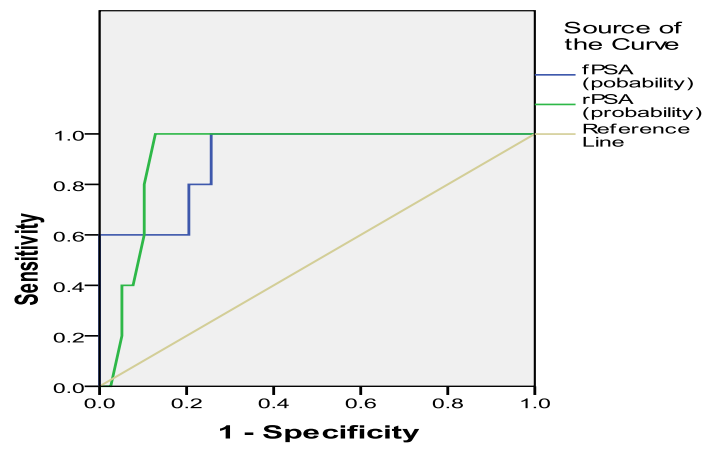

Diagonal segments are produced by ties.

The area under the curve AUC for both the fPSA and f/tPSA ratio was highly significant. The ratio PSA test was highly predictive (AUC $=0.921, p=0.002$ ) than free PSA (AUC=0.908, $\mathrm{p}=0.003$ ). The optimal sensitivity and specificity were $(80 \%, 90 \%)$ for the f/tPSA ratio and $(80 \%, 79 \%)$ for the fPSA. Cut-off points for the fPSA, cPSA, tPSA and f/tPSA ratios were not established because of the limitations in our data, which had a low prevalence of the prostate cancer cases.

\section{DISCUSSION}

The major limitation in this study was the small sample size as the prostate cancer cases in the study population are generally low. This is in accordance to the WHO (2002) data table for cancer impact by country that reported an incidence of 38/100 000 in Zimbabwe whereas in the United States 166/100 000 were reported. Another reason for low sample size than anticipated was that some participants could not afford the cost of referring biopsies to private pathologists. This resulted in our tests having reduced power. There are limited biopsies done at government hospitals due to shortage of both human and financial resources. This has been compounded by the socio-economic and socio-political dynamics whose cascade effect impacted negatively on health service delivery. The post year 2000 era heralded a phase of brain drain and reduced budgetary allocations to government institutions as a result of the international sanctions imposed on the Zimbabwean government. In this paper, cut off points could not be established for the different parameters. However, some meaningful conclusions were drawn from the data, whose information can be used to generate new 
hypothesis for further studies in the same area of study.

Here we found a prevalence of $11.4 \%$ for prostate cancer, which was slightly lower as compared to other studies within the same tPSA range ${ }^{16,17}$ this could be as a result of the methods used in the inclusion criteria. In this study a tPSA range of $3.0-10 \mathrm{ng} /$ $\mathrm{ml}$ was used while most studies included participants with any tPSA value. However, a study by Thakur et al. ${ }^{18}$ reported a prevalence of $13.0 \%$ although they did not use a specific tPSA range in their study. The information obtained in this study support finding from previous studies in terms of tPSA, fPSA, cPSA and $\mathrm{f} / \mathrm{tPSA}$ ratio relative to differences between cases of prostate cancer and other benign neoplasms. This research found BPH cases to have lower tPSA (mean 5.7 versus $6.2 \mathrm{ng} / \mathrm{ml}$ ) and cPSA (mean 3.9 versus $5.6 \mathrm{ng} / \mathrm{ml}$ ) than in prostate cancer cases but the differences are statistically not significant $(\mathrm{p}>0.05)$. In a retrospective study of 180 patients, Chen ZD et al. ${ }^{17}$ also came to the same conclusion since the mean value of tPSA was not statistically different between patients with prostate cancer and BPH $(\mathrm{p}>0.05)$.

The mean fPSA was significantly lower in prostate cancer than in BPH cases ( 0.3 versus $1.0 \mathrm{ng} / \mathrm{ml}$ ) and consequently the mean $\mathrm{f} /$ tPSA values (4.8 versus $16.2 \%$ )Sakai et $a l .{ }^{19}$ also reported that $\mathrm{f} / \mathrm{tPSA}$ ratio was significantly lower in prostate cancer patients than in BPH patients. The mean cPSA was lower in prostate cancer patients than in BPH patients (5.6 versus $3.9 \mathrm{ng} / \mathrm{ml}$ ) although the values were not statistically significant $(p>0.05)$. In their study of 54 patients, Tamimi et al. ${ }^{20}$ reported no significant association between high cPSA values and prostate cancers and they concluded that cPSA presented little advantage over tPSA for discriminating between BPH and prostate cancer in the population that they studied. However, such conclusions might arise due to small sample size as other researchers actually reported cPSA being statistically significant between patients with prostate cancer and $\mathrm{BPH}^{21}$

The sensitivity and specificity values were in the range of what has been found in other studies. Both fPSA and f/tPSA had high and equal sensitivity value of $80 \%$. However, the f/tPSA ratio had a significantly higher specificity ( $90 \%$ versus $79 \%$ ). Results for specificity were on the contrary as many of the studies have noted that these biomarkers have high sensitivity and low specificity in the tPSA range of less than $10 \mathrm{ng} / \mathrm{ml}$. A systematic review and meta- analysis reported a specificity of $18 \%$ in the $4-10 \mathrm{ng} / \mathrm{ml}$ range and $6 \%$ in the $2-4 \mathrm{ng} / \mathrm{ml}$ range at a sensitivity of $95 \%{ }^{21}$. The optimal cut off points for fPSA, cPSA and f/ tPSA ratio could not be established to classify individuals as having prostate cancer or not again as a result of low power in our study.
There is need to carry out cross-sectional studies 6major stake holders and reproductive health organizations may support such a $\mathrm{CaP}^{23,24}$ initiative. An interesting dimension during this cohort study would be to relate CaP to HIV as other researchers have found a positive correlation. ${ }^{25,26,27}$ Such an integral approach will maximize resource utilization whilst increasing project feasibility. ${ }^{28}$

\section{Conclusion}

This paper is in conformity with other reports that $\mathrm{f} / \mathrm{tPSA}$ ratio can aid in the diagnosing of prostate cancer in the $3-10 \mathrm{ng} / \mathrm{ml}$ range as compared to the use of tPSA alone. The use of $f / t P S A$ ratio was found to be more predictive because its association with the occurrence of prostate cancer which was highly significant $(\mathrm{p}<0.05)$. The use of cPSA remains controversial, hence warranting further study. The diagnostic ability of the use of the isoforms so as to reduce unnecessary biopsies was not ascertained as cut offs of these isoforms and their ratios could not be established. This could also have been a result in bias of the statistical methods, as most of the assumptions to carry them were not protected by the available data. To that end, results in this study cannot be used to make direct recommendations for clinical practices, but for the formulation of new hypothesis to be conducted in using larger cohorts. This also entails effective resource mobilization for an inclusive program that may be run along a national CaP awareness campaign in both urban and rural areas.

\section{Competing interests}

All authors declare that they have no competing interests.

\section{Authors' contributions}

HTM was involved in designing the study, supervision of fieldwork and data analysis. SU contributed in proposal writing, laboratory based assays and data analysis. PJ contributed in the discussion and data analysis. CM was involved in drafting the manuscript and discussion of the Public Health implications of the study. The final manuscript was read and approved by all authors.

\section{Acknowledgements}

The authors would like to express their gratitude to the Department of Chemical Pathology (University of Zimbabwe) and senior management at Premier Clinical Laboratories for constructive contribution and financial support. 


\section{REFERENCE} A. Twenty years of PSA: From Prostate Antigen to Tumour Marker. Rev Urol. 2007;9(3):113-123. | 3. Siegel R, Naishadham D, Jemal A. Cancer Statistics 2012. Cancer Journal. 2012;62:10 | 4. Loeb S, Catalona WJ, The next generation of prostate cancer detection. Clinical Laboratory News. 2007;33:3 | 5. Adhyam M, Gupta AK. A review on the Clinical Utility of PSA in Cancer of Prostate. Indian Journal of Surgical Oncology. 2012;3(2):120 | 6. D'Amico, A.V., Chem, M.H., Rochl, K.A. Preoperative PSA velocity and the risk of death from prostate cancer after radical prostatectomy. New England Journal of Medicine. 2004;351:125-135. | 7. Babaian RJ, Johnston DA, Naccarato W, et al. The incidence of prostate cancer in a screening population with a serum prostate specific antigen between 2.5 and $4.0 \mathrm{ng} / \mathrm{ml}$ : relation to biopsy strategy. Journal of Urology. 2001;165:757.| 8. Ganna, P.H., Hennekens, C.H., Stampfer, M.J. A prospective evaluation of plasma prostate-specific antigen ffor detection of prostate cancer. JAMA. 1995;237: 289-94. | 9. Moul JW, Sesterhenn IA, Connelly RR, et al. Prostate-specific antigen values at the time of prostate cancer diagnosis in African-American men. JAMA. 1995;274:1277. | 10. Morgan TO, Jacobsen SJ, McCarthy WF, et al. Age-specific reference ranges for prostate-specific antigen in black men. New England Journal of Medicine 1996;335:304. | 11. Oesterling JE, Jacobsen SJ, Chute CG, et al. Serum prostate-specific antigen in a community-based population of healthy men. Establishment of age-specific reference ranges. JAMA.1993;270:860.| 12. Partin, A.W., Bawer, M.K., Bartsch, G., etal. Complexed PSA improves specificity for prostate cancer detection; results of a prospective multicenter clinical trial. Journal of Urology. 2003;170:1787 | 13. Brawer MK, Meyer GE, Letran JL, et al. Measurement of complexed PSA improves specificity for early detection of prostate cancer. Urology journal. 1998;52:372 | 14. Catalona WJ, Smith DS, Ornstein DK. Prostate cancer detection in men with serum PSA concentrations of 2.6 to $4.0 \mathrm{ng} / \mathrm{mL}$ and benign prostate examination. Enhancement of specificity with free PSA measurements. JAMA. 1997;277:1452.| 15. Miller MC, 0'Dowd GJ, Partin AW, Veltri RW. Contemporary use of complexed PSA and calculated percent free PSA for early detection of prostate cancer: impact of changing disease demographics. Urology journal. 2001;57(6):1105-11. | 16. Ito K, Yamamoto T, Ohi M et al. Free/Total PSA ratio is a powerful predictor of future prostate cancer morbidity in men with initial PSA levels of 4.1-10 ng/ml. Urology journal. 2003;61(4):760-4. | 17. Chen ZD, Wei SM, Cai SL. Significance and limitations of free to total PSA in differential diagnosis of prostate cancer with total PSA level between 4 and $10 \mathrm{ng} / \mathrm{ml}$ Zhonghu Wei Za Zhi. 2004;42(10):593-6. | 18. Thakur V, Singh PP, Tamlwar M, Mukherjee V. Utility of free to total prostate-specific antigen (f/tPSA) ratio index of prostate carcinoma. Dis Markers. 2003-2004;19(6):287-92. | 19. Sakai I, Harada K, Hara I, Eto H, Miyako H. Limited usefulness of the free/total PSA ratio for diagnosis and staging of prostate cancer in Japanese men. International Journal Clinical Oncology. 2004;9(1):64-7. | 20. Tamimi W, Daftodar R, Mansi M, Alsaad K, Alarifi SA. Complexed and total PSA in patients with benign prostatic hyperplasia and prostate cancer. British Journal of Biomedical Sciencies. 2010;67(4):184-8.| 21. Roddam AW, Duffy MJ, Hamdy FC, et al. Use of prostate of specific antigen (PSA) isoform for the detection of prostate cancer in men with a PSA level of 2-10ng/ml: systematic review and meta-analysis. Eur Urol. 2005;48(3):386-99. | 22. Jackson DD, Owens OL, Friedman DB, Hebert JR. An Intergenerational Approach to Prostate Cancer Education: Findings from a Pilot Project in the Southern USA. J Cancer Educ 2014, Feb 22 (In press). Available from: http://www.ncbi.nlm.nih.gov/pubmed/24557505 [Accessed 30 March 2014].| 23. Muray JP, Wenger AFZ, Downes EA, Terrazas SB. Educating Health Professionals in Low Resource Countries: A Global Approach. Available from https:// www.cartercenter.org/resources/pdfs/news/health_publications/ephti/EPHTIBook-Preface.pdf [Accessed 04 March 20114]. | 24. Marwa B, NjauB, Kessy I and Mushi D. Feasibility of Introducing compulsory community health fund in low resource countries: views from the communities in Liwale district of Tanzania. BMC Health Services Research (2013) 13:298. Available from: http://www.biomedcentral.com/1472-6963/13/298 [Accessed on 8 March 2014]. | 25. Pantanowitz L, Bohac G, Cooley TP, Aboulafia D and Dezube BJ. Human immunodeficiency virus associated prostate cancer: clinicopathological findings and outcome in a multi-institutional study. BJU International June 2008;101(12):1519-1523. | 26. Wosnitzer MS and Lowe FC. Management of Prostate Cancer in HIV-positive patients. Nat Rev Urol. 2010;7(6):348-57. | 27. Newcomb-Fernandez J. Cancer in the HIV-Infected Population. Available from: http://www.thebody.com/content/art16834.html [Accessed on 03 March 2014]. | 28. Stenberg K, Elovainio R, Chisholm D, Fuhr D, Perucic A, Rekev D, et al. Responding to the challenge of resource mobilisation-mechanisms for raising additional domestic resources for health. World Health Report. 2010. Background Paper No. 13. Available from: http://www.who.int/healthsystems/topics/financing/healthreport/13Innovativedomfinancing.pdf [Accessed 15 March 2014]. I 